\title{
Biologists sound warning on species conservation
}

[WASHINGTON] A small but influential group of conservation biologists last week warned that efforts to make the US Endangered Species Act (ESA) more friendly to property owners "will not further the Act's goals unless those measures are implemented in a scientifically sound manner".

The ESA lets landowners develop land that includes protected habitats provided they develop Habitat Conservation Plans (HCPs) which mitigate the harm this causes protected species by setting aside habitats or making other actions to protect species in the long term. But better scientific review of such plans is needed, warns an ad-hoc group of nine biologists and geneticists led by Dennis Murphy of Stanford University. The group sent its report last week to Katie McGinty, head of the White House Council on Environmental Quality, and congressional environmental committee chairmen.

The use of HCPs has proliferated during the Clinton administration, which has tried to ease political tensions between landowners and environmentalists. But the increase in the scale of the plans, many of which cover many species and enormous areas of land over long periods, has concerned environmental scientists. "Many recent HCPs have been developed without adequate scientific guidance," write the biologists. They say the plans have the potential to contribute to, rather than alleviate, threats to listed species and their habitats.

The group calls for the creation of a standing body of independent scientists to review large and complex HCPs. The comprehensiveness of such reviews, they write, should be "appropriate to the size and duration of the plan". Any multiple-species HCPs must also include adequate research and monitoring programmes, with an "assured source of funds".

To be scientifically credible, the plans must "clearly articulate measurable biological goals and demonstrate how those goals will be attained". HCPs should not undermine the recovery of listed or vulnerable species by simply preserving their endangered status on isolated parcels of land.

The biologists also recommend increased funding and improved training for govern-

\section{Discoverer of comet bemoans lack of jobs}

Alan Hale, the co-discoverer of the bright comet appearing in the sky this spring, is using his new-found celebrity not to talk about the wonders of the Universe, but to call attention to the difficulties facing younger scientists. In press interviews and in an open letter on the Internet, Hale, a 38year-old astronomer, denounces the "abysmal" opportunities facing scientists of his generation.

"Unless there are some pretty drastic changes in the way that our society approaches science and treats those of us who have devoted our lives to making some of our own contributions, there is no way that I can, with a clear conscience, encourage present-day students to pursue a career in science," he wrote in his letter, which went out to various electronic newsgroups in late March.

Since discovering the comet named after him and amateur astronomer Thomas Bopp in 1995, Hale has used his many interviews in the media to highlight the difficulties that young scientists with PhDs face in finding well-paid jobs. Hale says that reporters often do not use this part of the interview. But he says he intends to continue trying to raise awareness.

Hale searched in vain for a university position several years ago. He eventually

\section{IMAGE UNAVAILABLE FOR COPYRIGHT REASONS}

Hale: 'abysmal' situation means that he cannot encourage students to pursue a career in science.

took a low-paid job in a science museum in New Mexico before creating his own research and education organization, the Southwest Institute for Space Research, in 1993.

He says he knows that others have experienced similar problems in "pursuing any kind of decent career within science". A request for "horror stories" from other young scientists has yielded hundreds of responses, he says.

T.R.

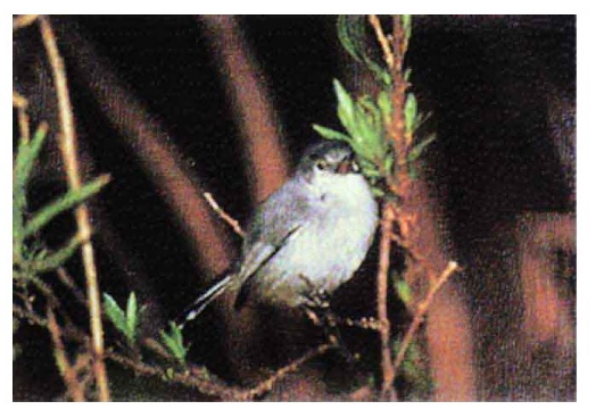

At risk: the Coastal Californian Gnatcatcher is one endangered species that could be affected.

ment officials in charge of enforcing the ESA, principally at the Fish and Wildlife Service and the National Marine Fisheries Service.

Further concerns have been raised by assurances given by Interior Secretary Bruce Babbitt in 1994 that landowners would have "no surprises" in complying with the Act, meaning that, once the government had approved an HCP, it would not impose additional requirements on the property owner. The biologists argue that habitats and species will be lost unless conservation plans can be amended.

The biologists agree that, "with essential stipulations, landowner-friendly initiatives can assist in meeting [the ESA's] goals". But they prefer to replace the 'no surprises' policy with a 'fair assurances' policy, which would allow an HCP to be changed based on new scientific information. But the scientists concede that the public, rather than landowners, might reasonably be asked to pay any costs associated with amending plans after they have been approved.

The group of biologists includes Peter Brussard of the University of Nevada, Michael Soulé of the University of California at Santa Cruz, Reed Noss of Oregon State University, and Gary Meffe of the Department of Energy's Savannah River Ecology Laboratory. Murphy, currently president of the Society for Conservation Biology, invited them to Stanford in February to hammer out a 'consensus document' that could help add scientific objectivity and moderation to an increasingly polarized debate.

The ESA is up for review, but few are optimistic that this will happen quickly or easily. A bipartisan bill penned by two Senators on opposite sides of the issue - Dirk Kempthorne (Republican, Idaho) and John Chafee (Republican, Rhode Island) — has been in 'discussion draft' since early this year, with no apparent agreement between environmentalists and property rights advocates. The 'no surprises' policy comes up for a 60-day public comment period this spring.

Murphy invited only scientists who had worked on large conservation plans involving private property to join the group. $\mathrm{He}$ himself recently led a scientific review panel advising on a large and controversial HCP in southern California.

Tony Reichhardt 